\title{
O Funcionário Público e a Consolidação Estatutária
}

\author{
Francisco José de Souza \\ (Da D.C. da Contadoria Geral da República) \\ INTRODUÇ̃̃o
}

\begin{abstract}
A Públicos, ensejo do anunciado Congresso Nacional de Servidores , deliberamos concorrer com esta dissertação, menos pela Associação dos Servidores Civis do Brasil - do que no intuito de prestigiar a promoção congressional, trazendo a debate o importante problema da consolidação estatutária do servidor público, ante a proliferação de leis materiais ou substantivas posteriores, reformuladoras de direitos e deveres do funcionalismo civil da União.
\end{abstract}

Temática de vera significação nos dominios do Direito Público, interno, com raízes no direito essencialmente politico - o Constitucional - corroborante da inferência de que a função pública jurídica e funcionalmente estruturada é condição ou requisito essencial ao pretendido êxito da programação administrativa.

Isto porque a natureza das relações entre o Direito Administrativo e o Constitucional é de tal intimidade, que os adeptos da teoria organicista doutrinavam caber a êste a anatomia e àquele a fisiologia do Estado.

Aceitando-se a premissa, é plausivel admitir-se que, entre serviço público e função pública também há perfeita conotação de idéias e, portanto, correlação de matérias, pois, na lição do douto Bielsa, ${ }^{(1)}$

“... la suerte del servicio publico depende casi interamente de la organización de la función publica, que és presupuesto necesario de servicio." (Grifado no original)

(1) Rafael Bielsa - La Función Publica, pág. 72, Buenos Aires, 1960. 
De fato, um serviço público capacitado a atingir um alto indice de produtividade deve combinar, na proporção ideal, o aparelhamento pessoal especializado com o material de padronização simplificadora da rotina de trabalho.

Sem dúvida, para colimar-se êsse objetivo é de mister o emprêgo seletivo ou de triagem dos melhores sistemas de organização cientifica do trabalho aliado às regras norteadoras do sucesso nas relações humanas, com o fim de atender-se ao interêsse público, alfa e ômega da administração, porque, como enfatiza o citado professor argentino $\left(^{2}\right)$ - "La causa de todo servicio és el interés publico." (O grifo é do original)

E outra não poderia ser a orientação administrativista moderna perfilhada pelo professor Emmerich, $\left({ }^{3}\right)$ para quem:

"O serviço público deve verdadeiramente pertencer à sociedade a que serve, compartilhando de sua cultura, de seus valôres, de seus problemas e de suas ambições."

Logo, a sintese refletora do serviço de alto nível depende do bom aproveitamento da capacidade não ociosa, vale dizer, realizadora, dos recursos humanos, "scilicet": o funcionário, que, na definição do clássico Trotabas, $\left({ }^{4}\right)$

\begin{abstract}
$\because$... est fonctionaire public la personne qui, nommée dans un emploi permanent, a eté titularisée dans un grade de la hierarchie des cadres d'une administration publique."
\end{abstract}

\title{
O REGIME ESTATUTÁRIO DO FUNCIONÁRIO PÚBLICO
}

Como o empirismo (ação ou pragmática) precede a teoria (raciocinio) que o interpreta e explica sua natureza instintiva e não volitiva ou cognitiva, ou, ainda, como quer Bergson, produto da "intuição criadora", assim também o Direito, emergente do fato social - "ius ex facto oritur" - reclama a preexistência do caso concreto, da situação "de facto", para que a consciência juridica, plasmada sob os influxos dos principios gerais ou universais do direito, elabore a norma geral e abstrata que irá reger a relação ou situação jurídica subjetiva, ou o instituto, conforme a natureza do sistema politico e a cobertura que lhe der a ordem social imperante.

(2) Rafael Bielsa - Idem, pág. 129. Rio, 1962 .

3) Herbert Emmerich - Manual de Administração Pública, pág. 23.

(4) Luis Trotabas - Manuel de D. P. et Administratif, pág. 116, 
Dentro dessa ordem de considerações éticas ou deontológicas do direito, talvez seja possivel dar relêvo à assertiva de que, no provimento dos cargos públicos tem imperado um critério dúbio ou flexível: ora se norteia pelo atendimento puro e simples da necessidade mais ou menos imediata do serviço; ora se preocupa apenas com o problema pessoal de preenchimento da vaga, o que, de certo modo, afirma o conceitualismo do publicista argentino, baseado na idéia de que - "El funcionario existe para la función y no la función para el funcionario". (5)

Eis que o nepotismo é a lepra que corrói o serviço público. Os legisladores demagógicos, quando não agem em causa própria, fazem da Constituição "tabula rasa" (para usarmos da expressão cunhada por JoHN LOCKE) na qual êles imprimem, a seu talante, todos os preceitos que possam coonestar o compadrio, afilhadisms, "pistolão" ou que nome tenha essa "diátese cancerosa" do serviço público.

Haja vista a violação iterativa da regra proibitiva do art. 185 da Carta Politica Federal, com a pretendida efetivação de interinos nomeados "ad instar" do artigo 12 da Lei $n^{\circ}$ 1.711-52, mediante leis especiais que, - "et nunc eruđimine" - insòlidamente derrogam as exigências do pacto fundamental.

Brotam, então, como cogumelos na alfombra, isto é, em superabundância, as leis de amparo a semelhantes situações subjetivas do funcionalismo ante o conteúdo eleitoreiro de suas disposições.

Outras vêzes, seguindo-se o modêlo "made in USA", onde a corrupção era o traço marcante da vida politica, $\left({ }^{6}\right)$ no setor do funcionalismo adotavam-se práticas esdrúxulas caracterizadas pela insegurança ou instabilidade funcional, como a do famigerado "principio da rotatividade" ou sistema de espólio, que admitia a substituição dos servidores nomeados na administraçâo do partido político vencido nas eleições, pelos correligionários da facção vitoriosa. Era, como se vê, a redistribuição imoral dos cargos do serviço público proporcionalmente à fôrça dos partidos politicos, não se permitindo o estabelecimento do instituto da estabilidade. $\left({ }^{7}\right)$

Mas, não se pense que o sistema de provimento de cargos denominado - "senatorial courtesy" - foi superado ou banido, por anacrônico, dos processos políticos de nomeação de funcionários, porque dificilmente o será, máxime nos paises subdesenvolvidos, de baixo nível de instrução e grande mobilidade política.

O que se obtém dêsse "caldo de cultura" é, como não poderia deixar de ser, o bacilo do culto à incompetência muito ao gôsto

(5) Rafael Brelsa - Obr. Cit.. pág. 133.

(6) JoAquim Nabuco - Minha Formação. "Passim", S. Paulo, 1934.

(7) Pinto PessoA - Classificação de Cargos, pág. 18, Rio, 1962. 
dos manipuladores dos negócios administrativos, surdos à advertência do Prof. LAsKI $\left({ }^{8}\right)$ para quem:

"Confundir rotina com eficiência e antigüidade com experiência são sempre os perigos que ameaçam o funcionalismo."

No Brasil, também se acastelaram os mesmos vícios, que inquinam as leis do serviço público, porque surgem ao sabor das necessidades imediatistas ou ocasionais da Administração e, quanto ao provimento, não era raro olvidar-se a velha e moralizadora praxe inglêsa - "The right man in the right place."

A êsse respeito, em outro trabalho $\left(^{9}\right)$ citamos os depoimentos de José Inácio Borges e Ruy Barbosa, ambos Ministros da Fazenda e que guardam, entre si, eloqüente identidade de pontos de vista.

Vejamos o que dizia o ministro do Império:

"Observo que com pequena paga não se convida a quem tem préstimo, e introduzir nas repartições quem não tem aptidão é perturbar o serviço dos que o podem prestar." $\left({ }^{10}\right)$

Ruy, ministro do Govêrno Provisório da República, depõe:

"O sistema usual entre nós consistia em encher as repartições de pessoal nem sempre idôneo, mas sempre excessivo e, conseguintemente, mal remunerado. São óbvios os inconvenientes, que dessa situação resultavam." (11)

Não é que queiramos cair no juízo precipitado e por isso mesmo temeràriamente conclusivo, de que é coisa de somenos dificuldade a implantação de um sistema coordenador de preceitos legais visando à disciplina das relações entre o Estado e seus servidores, ou melhor, desde a fase seletiva ou concursiva até a de provimento dos cargos e, dai por diante, a fixação de encargos e direitos, segundo o cânon básico da justiça comutativa.

Tanto isto é verdade que basta a citação de nosso perene ou costumeiro comércio com o assunto, não desconhecendo, ademais, a notícia do conciso histórico feito por TEMístocles

(8) HAROLd J. LASKI - Introdução à Politica, pág. 77.

(9) Francisco José de Sousa - Uma Contribuição ao Estudo da Contabilidade Pública, pág. 46, Recife, 1960.

(10) Citação de Oscar Bormann, no prefácio ao Relatório do Ministro da Fazenda Ruy Barbosa, Rio, 1949.

(11) Ruy B BRBosa - Relatório do Ministro da Fazenda, Tomo III pág. 271, Rio, 1949. 
Brandão Cavalcanti, $\left({ }^{12}\right)$ para ver-se que foi preciso o transcurso de nada menos que três decênios (desde o projeto JustrNIANO SERPA, de 1907) para se chegar ao Decreto-lei $n^{\circ} 1.713$, de 28 de outubro de 1939, que - "Dispõe sôbre o Estatuto dos Funcionários Públicos Civis da União."

Também é de justiça ressaltar a criação do Departamento Administrativo do Serviço Público (D.A.S.P.) como órgão diretamente subordinado à Presidência da República, pelo Decreto-lei $n^{\circ} 579$, de 30 de julho de 1938 , como um grande passo no sentido de efetuar-se o saneamento moral (infelizmente nem sempre alcançado) no processo de admissão ou ingresso e na organiza. ção do serviço público.

Com o ressurgimento da democracia política, como forma de govêrno, após a segunda guerra mundial, passou o Brasil a reger -se pela Constituição de 18 de setembro de 1946, razão por que se tornou imprescindivel a revisão, pelo Congresso Nacional, do citado Estatuto do Funcionalismo Civil, que passou a ser regulado pela Lei $n^{\circ} 1.711$, de 28 de outubro de 1952 .

Ao ordenamento jurídico-político do direito estrutural ou tundamental, sabemos, cabe apenas dar as normas "in genere", isto é, gerais e sintéticas sôbre o provimento ou ingresso do funcionalismo e as garantias referentes à percepção de vencimentos ou remuneração, estabilidade e aposentadoria (artigos 184 "usque" 194 da Carta Magna), deixando à lei ordinária o estabelecimento das normas especiais que formam o liame da contextura do serviço público, em nosso caso o debatido Estatuto do Funcionalismo Civil da União, regido pela Lei n 1.711 52 .

Tudo isso, porém, é relativo ou, como dizia SHAKespeare "words, words" - pois o funcionalismo é a eterna vítima de leis criadoras de privilégios e discriminações.

Eis que, em abono da afirmativa, vem, a talho de foice, o caso da recente Lei $n^{\circ} 4.950-A$; de 22 de abril último, promulgada pelo Presidente do Senado Federal, que, a pretexto (louvável, de resto), dé estimular determinadas carreiras ou profissões técnicas, estabeleceu um salário inicial compativel com os deveres, grau de responsabilidade e padrão de vida, com base no maior saláriominimo vigente no País, e calculado com o emprêgo do coeficiente ou multiplicador 6 ou 5 , conforme se trate de cursos universitários de mais ou de menos de 4 anos, que especifica, excluindo, porém, outros profissionais em igualdade de condições e que sa. tisfazem os requisitos legais, como os contadores, os economistas, os atuários, "et caterva", profissões de crescente prestígio à medida que se processa o desenvolvimento econômico-social da

(12) Temístocles Brandão Cavalcanti - O Funcionário Público e o seu Regime Juridico, vol. I, págs. 101/103, Rio, 1958. 
Nação, e de elevados índices de demanda seja nas untversidades seja no mercado de trabalho.

Registra-se então que, para fazer justiça a uns o legislador postergou o direito de outros e, o que é mais grave, feriu os princípios constitucionais de igualdade perante a lei (art. 141, $\left.\S 1^{\circ}\right)$; a não distinção entre profissionais (art. 157, § $1^{\circ}$ ), e, sobrepairando a tudo a idéia de justiça e eqüidade, que se exterioriza no principio da isonomia salarial, já aceita na Consolidação das Leis Trabalhistas (art. 5 combinado com o artigo 461, do Decreto-lei $n^{\circ} 5.452$, de $1^{\circ}$ de maio de 1943).

Anomalia é, outrossim, a lacuna do principio institucional da paridade no estipêndio dos funcionários de igual categoria dos três Podêres, por falta de expressa cogência no texto Constitucional, permitindo o desnivel salarial do servidor do Poder Executivo, que já o havia perdido para os militares, com a derrogação da Lei $n^{\circ} 4.242-63$.

E até agora, não obstante o "writ "do artigo 25 do Ato Institucional $\mathrm{n}^{\circ} 2$, de 27 de outubro de 1965 , estabelecendo - "... a partir desta data, o principio da paridade na remuneração dos servidores dos três Podêres da República, ..." nem mesmo assim procedeu-se ao nivelamento especifico do estipêndio, que é

“... substancialmente um salário. É o preço do trabalho e tem, ao mesmo tempo, o caráter de renda alimentar." (13)

Essa "legiferação" desordenada tem, contudo, o grande mérito de evidenciar a necessidade de proceder-se à imediata com. pilação das normas jurídicas esparsas, muitas vêzes contraditórias, antinômicas ou conflitantes, que, alargando a área de insegurança no seio do funcionalismo, vão, por fim, tumultuar a boa ordèn imprescindivel à realização do serviço público.

\section{A SISTEMÁTICA DO ESTATUTO E LEIS EXTRAVAGANTES}

O Estatuto é, formal e substancialmente, um conjunto mais ou menos orgânico, contendo disposições gerais e específicas relativas aos agentes da Administração Pública. Na conformidade do que estabelece a Lei $n^{\circ} 1.711$, de 28 de outubro de 1952, por seu intermédio, instituiu-se - "o regime jurídico dos funcionários civis da União e dos territórios", como reza o artigo $1{ }^{\circ}$.

O referido diploma legal está dividido em seis títulos e começa pelas disposições preliminares; o segundo trata do pro vimento e da vacância dos cargos públicos; o terceiro fixa os di-

(I3) CARLos S. de Barros JúnIor - Dos Direitos adquiridos na relação do Emprêgo Público, S. Paulo, 1955. 
reitos e vantagens do funcionário; o quarto, o regime disciplinar; o quinto regula o processo administrativo e sua revisão, e o sexto, finalmente, cura das disposições gerais e transitórias.

Aprofundando a pesquisa, veremos que na Lei $n^{\circ} 1.711$, sob exame, estão previstas situações novas no serviço público, a serem traduzidas em leis e regulamentos, como é o caso do "full time", assim enunciado no artigo 244 das "disposições gerais":

"Poderá ser estabelecido o regime do tempo integral para os cargos ou funções indicadas em kei."

Nas "Disposições Transitórias" vamos encontrar a matriz das alterações mais importantes e já em vigor: o artigo 256, por exemplo, dá o prazo de doze meses para o Govêrno promover a execução do plano de assistência mencionado no art. 161; o parágrafo $2^{\circ}$ do artigo 257 fixa o têrmo de doze meses para o Exe. tivo apresentar nova codificação alusiva aos extranumerários, de resto coisa superada, e, por fim, o artigo 259 trata do "plano de classificação dos cargos do Serviço PúBlico Federal, com base nos deveres, atribuições e responsabilidades funcionais", que de. veria ser apresentado ao Congresso Nacional dentro de dois anos da publicação" da lei, consoante a redação do parágrafo único.

Em decorrência, novos institutos jurídicos surgiram mediante leis votadas pelo Legislativo e sancionadas pelo Executivo, valendo citar, dentre as mais importantes, as seguintes:

a) Lei $\mathrm{n}^{\circ}$ 3.373, de 12 de março de 1958, que "Dispõe sôbre o Plano de Assistência ao Funcionário e sua Família, (...) na parte que diz respeito à Previdência";

b) Lei n 3.780, de 12 de julho de 1960, que "Dispóe sôbre a Classificação de Cargos do Serviço Civil do Poder Executivo, estabelece os vencimentos correspondentes, e dá outras providências";

c) Lei $n^{\circ} 4.503$, de 30 de novembro de 1964, que criou u Departamento de Arrecadação, unificou a carreira de Exator, incluiu os Fiẻis do Tesouro do Ministério da Fazenda no Grupo Ocupacional AF 300 - Fisco, "e dá outras providências";

d) Lei $\mathrm{n}^{\circ} 4.345$, de 26 de junho de 1964, que "Institui novos valôres de vencimentos para os servidores públicos civis do Poder Executivo e dá outras providências";

e) Lei $\mathrm{n}^{\circ} 4.863$, de 29 de novembro de 1965 , que reajustou os vencimentos dos servidores civis e militares e dá outras proyidências, e

f) Lei $n^{\circ} 4.950-A$, de 22 de abril de 1966, que "Dispõe sôbre a remuneração de profissionais diplomados em Engenharia, Quimica, Arquitetura, Agronomia e Veterinária." . 
Como todos sabemos, a Lei n $3.780-60$ é um diploma jurídico importante não só para o funcionalismo civil, como, principalmente, para o serviço público, em virtude da "mens legis" de ordem estruturadora, sendo, quiçá, a mais significativa medida tomada pela Administração, no sentido de ordenar o sistema de cargos e funções do serviço público. Mesmo porque é principio comezinho de Direito Administrativo de que o conceito amplo de serviço público contém o menor ou estrito, - a "função", de carátes imediato ou essencial, pois, segundo o concebe Kammerer, admi nistrativista alemão: $\left.{ }^{(14}\right)$

“... exercer uma função do Estado é realizar um dos deveres, um dos fins para os quais existe o Estado. E portanto, na realidade, a tradução material de um serviço qualquer à causa pública."

Prosseguindo na faina exegética da precitada Lei $n^{\circ} 3.780-60$, observaremos que, "ab initio", veio modificar o substrato das "Disposições Preliminares" do Éstatuto de 1952, seja pela amplia. são do alcance, seja pela reformulação do sentido, seja, enfim, pela introdução de outros conceitos, indo até a análise definidora de "cargo", "classe", "carreira", "quadro", etc., bem assim as noções das novas figuras de "série de classes", "grupo ocupacional", "serviço" e "nivel universitário."

O sistema de classificação de cargos aprovado pela Lei número $3.780 / 60$, como vimos, abrange o serviço e, dentro dêste, o grupo ocupacional, o código, a série de classes, a característica destas e o acesso à carreira principal. Salutarmente, a lei fêz desaparecer do serviço público a figura do extranumerário.

O Capitulo V ministra as regras de enquadramento. Os de números VII e VIII cuidam da promoção do funcionário à classe superior e do acesso à carreira principal; os Capitulos IX e X regulam, respectivamente, a instituição dos órgãos de classificação de cargos e a readaptação de funcionário, nos casos e nas condições previstas na lei.

Já o Capitulo XI enfrenta o aludido problema da implantação do tempo integral e dedicação exclusiva, inovação de largo e imprevisivel alcance, pois tem por escopo a maior eficiência do ser* viço público de natureza técnico-cientifica, de pesquisa e de magistério, porém de cuja prática só agora se ensaiam os primeiros passos, de acôrdo com os Decretos executivos números 57.744 , de 3 de fevereiro e 58.095, de 28 de março do corrente ano.

Por sua vez, a Lei n 4.345-64 não se cingiu à mera correção salarial do funcionalismo civil da União. Muito ao contrário, interpretando-se a sistemática de sua construtura vamos descobrir

(14) "Apud" Temístocles B. Cavalcanti - Obr. cit., vol. I, pág. 93. 
o sadio propósito do legislador em corrigir distorções ou desacertos de leis anteriores.

Assim é que, elevando de 18 para 22 os niveis dos cargos efetivos, reservou, contudo, os quatro últimos para as carreiras de grau superior; extinguiu o triênio - a chamada progressão horizontal - e ampliou a compreensão da antiga gratificação adicional por tempo de serviço, reestruturando-a na base do qüinqüênio de serviço, com o percentual de cinco $(5 \%)$ até o limite de sete; estabeleceu, outrossim, o horário semanal de trabalho para os cargos de chefia e fixou os vencimentos de ministros, secretários-gerais, professôres catedráticos, diplomatas, “et reliquia."

Não esqueceu, a lei, o caso dos tesoureiros-auxiliares, classificando-os nos níveis 16 e 18 , passando a denominar-se, junto com os conferentes de valôres do Ministério da Fazenda - fiéis do tesouro, aliás enquadramento êsse modificado pela Lei número 4.503-64, conforme a remissão de item anterior, que o transferiu para o grupo ocupacional Fisco; o art. 18 limita o montante dos proventos do pessoal sujeito ao regime de remuneração, inclusive as participações em multas, aos vencimentos dos Ministros de Estado.

Ainda, a lei, mediante condições que fixa, é aplicável aos servidores das autarquias federais, sociedades de economia mista, dos Territórios e da Prefeitura do Distrito Federal, estendendo-se, também, aos aposentados e aos em disponibilidade.

Por derradeiro, determina a revisão do Plano de Classificação dos Cargos do funcionalismo civil aprovado pela Lei número 3.780-60, devendo o projeto basear-se no censo dos servidores de que cogita a Lei $n^{9} 4.242$, de 17 de julho de 1963, a cargo do Instituto Brasileiro de Geografia e Estatística em colaboração com o D.A.S.P., e que se executou a 31 de maio último, segundo as normas baixadas com o Decreto $n^{2} 58.297$, de 2 de maio de 1966 . O prazo de apresentação do prefalado projeto ao Congresso Nacional é de cento e vinte (120) dias após a conclusão do recenseamento.

\section{A CONSOLIDAÇÃO ESTATUTÁRIA E SUA APLICAÇÃO NOS ESTADOS E MUNICÍPIOS}

Dos antecedentes expostos chegamos à conseqüência da proposição: o Estado, os servidores e o público em geral vêem-se às voltas com a pluralidade de normas retoras do regime jurídico. administrativo do funcionalismo civil da União, tôda vez que há algo a opinar sôbre determinado fato; fundamentar um estudo, relatório ou parecer; justificar um arrazoado; apoiar uma decisão "in concreto" e, até mesmo, quando se deseja uma consulta rápida 
e emergente. Êsse emaranhado de leis esparsas leva muitas vêzes - funcionário informante de processo a aduzir ou elaborar seu raciocinio sôbre falsas premissas ou fundações movediças, de dispositivos legais derrogados e, outras vêzes, ab-rogados ou de revogação total.

Dai resulta a inquestionável vantagem da unicidade conso. lidadora sôbre o polimorfismo ou pulverização legal. Então, o pensamento reflexivo (de que fala John Dewey) aponta-nos o único caminho certo para chegar-se a um grau razoável de perfeição: o recurso ao criativismo do legislador, de que surgirá a figura jurídica da consolidação, que, sem as inconveniências da rigidez de um código, reunirá tôdas as leis em vigor num só corpo normativo.

Porque, sendo a consolidação obra unificadora e coordenadora do direito objetivo, como escreve Ruy Cirne Lima,

“... não modificam o grau de eficácia na hierarquia das fontes. Destinam-se apenas a dar a conhecer as dis. posições consolidadas." ( $\left.{ }^{15}\right)$

Se, no plano federal, o escólio que vimos tecendo da legislação nos aponta a situação confusionista dominante, nos Estados e Municipios as dificuldades não parecem de somenos importância no particular de que estamos versando (funcionalismo) porque o estatuto dos servidores daquelas pessoas jurídicas de direito público interno acompanha, "pari passu", as diretrizes da federal.

É que, dada a autonomia política e financeira outorgada pela Constituição, os Estados-Membros e os Municipios têm competência para organizar seus próprios serviços administrativos e, para que o municipio fique indene à pressão estatal, a lei supcrior vai ao extremo de permitir a intervenção no Estado, segundo o artigo 7\%, VII, "e", da Constituição Federal de 18 de setembro de 1946 .

Se assim é, se a legislação federal influencia a dos estados e municipios, no tocante ao regime jurídico do funcionamento civil, pode-se afirmar que, se a lei vier enfeixar as normas legais extravagantes, consolidando-as ou compilando-as, igual iniciativa terão os Estados e Municipios, para solucionarem seus problemas tipicos de pessoal.

\section{CONCLUSÕES}

Aceitando-se, porventura, seja dedutivamente conclusivo o raciocínio desenvolvido ao longo desta análise interpretativa do (15) RuY CIRNE LIMA - Sistema de Direito Administrativo Brasileiro,
pág. 96, 1953. 
regime jurídico do funcionalismo civil da União, será então possivel admitir que:

a) em seu tempo, o Estatuto de 1952 representou um marco digno das tradições jurídicas de nosso pevo;

b) contudo, as tendências modernas orientadoras do serviço pública e acolhidas pelo Poder Executivo impelem-no a recorrer à criação de novos institutos legais, para evitar a superação ou o enfraquecimento da estrutura funcional de seus servidores;

c) ainda, o irreversivel "devenir" ou evolucionismo das ca-

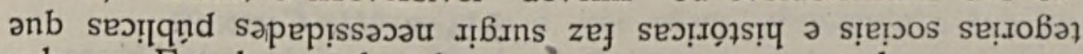
cabe ao Estado satisfazê-las, quer ao povo em geral, quer, particularmente, ao seu funcionalismo, do qual depende, em grande parte, o êxito da Administração Pública.

Concluímos, pois, pelo acêrto da iniciativa que visa à fusão ou compilação de tôdas as leis extravagantes (em relação ao Estatuto, já se vê), porque suas premissas nos levam à ilação de que a simplicidade decorrente da of'ganização favorecerá a solução, rápida e exata, dos problemas do funcionalismo, colocando ademais a Administração Pública nas condições ideais que propiciam a realização do "bem comum." 